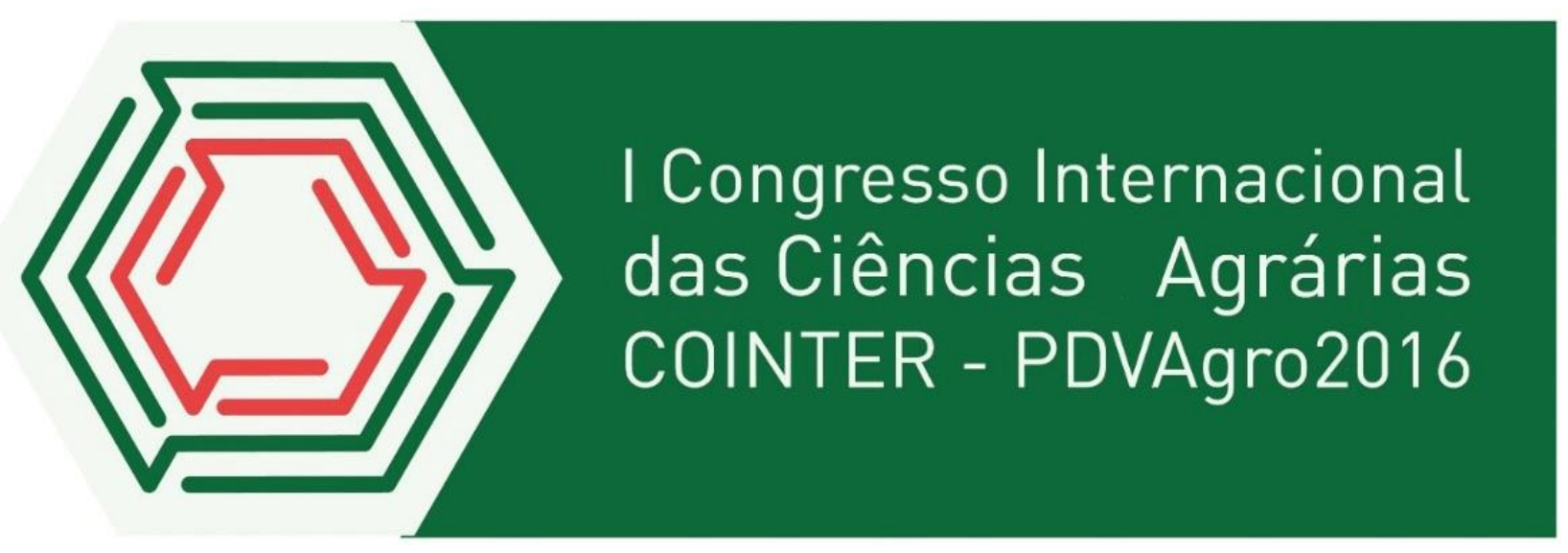

\title{
UMA ANÁLISE DOS ELEMENTOS NECESSÁRIOS PARA PROMOÇÃO DA CAPACITAÇÃO E INOVAÇÃO DO ARRANJO PRODUTIVO LOCAL DE AGRICULTURA FAMILIAR EM PERNAMBUCO
}

\author{
Apresentação: Comunicação Oral \\ Joás Tomaz de Aquino'; Vanessa de Cássia Lima da Silva²
}

\begin{abstract}
Resumo
A presente pesquisa tem como objetivo principal analisar os elementos necessários no delineamento da política de capacitação para a inovação do APL de Agricultura Orgânica no estado de Pernambuco. Caracterizando-se como um estudo de caso para identificar as principais demandas que o APL possui e que condicionam a sua inovação no cenário de Pernambuco. $\mathrm{O}$ método utilizado foi à análise de conteúdo por proporcionar uma descrição clara, sistemática e interpretativa do objeto de estudo esclarecendo as suas diferentes características e extraindo a sua significação, a partir de pesquisas documentais e bibliográficas. Apesar do presente APL ser identificado como invisível pelas políticas governamentais, recentemente foram identificadas atores políticos que agem sobre ele, condicionando o seu desenvolvimento, atendendo as suas principais demandas e amenizando as desigualdades existentes, pois a pobreza não se trata apenas de um problema que envolve comunidades locais, mas que tem mobilizado todas as esferas do poder e tem instigado várias medidas para sanar esse mal social.
\end{abstract}

Palavras-Chave: agricultura, arranjo produtivo local, capacitação, inovação.

\section{Introdução}

As políticas públicas têm se constituído em elementos estruturadores do desenvolvimento econômico e social de países ao longo do século XX. Entretanto, no caso brasileiro, como ressaltou Celso Furtado (1978), nesse período o país cresceu, modernizou-se, mas não se desenvolveu, pois o desenvolvimento somente ocorre quando é capaz de fazer do homem um elemento de transformação, passível de agir tanto sobre a sociedade como sobre si mesmo e de realizar suas potencialidades. Consequentemente, o que caracteriza o desenvolvimento é o projeto social que lhe é subjacente. Assim, quando se dá prioridade à efetiva melhoria das condições de vida da maioria da população é que o crescimento pode se metamorfoseia em desenvolvimento.

\footnotetext{
${ }^{1}$ Mestre em Administração, Universidade Federal de Pernambuco, joastomaz@ outlook.com

${ }^{2}$ Bacharel em Ciências Econômicas, Universidade Federal Rural de Pernambuco, nessacsilva@ hotmail.com
} 
O século XXI tem sido marcado pelo desafio do Brasil dinamizar o desenvolvimento em diversas escalas territoriais, cabendo ao Estado a sua promoção, isto é, criar condições de que em todo o território nacional não apenas o crescimento econômico seja potencializado, mas fundamentalmente as desigualdades sociais sejam diminuídas. Este desafio transformador não é apenas competência de governos, mas fundamentalmente uma meta a ser alcançada pela sociedade brasileira, que cônscia de suas opções deve identificar e criar possibilidades políticas para concretizar aspirações coletivas considerando especificamente em âmbitos locais e regionais. O desenvolvimento nacional é, assim, dependente de políticas e institucionalidades territoriais à medida que diferentes atores locais podem articular o desenvolvimento endógeno e contribuir para a geração e a distribuição de riquezas (BOISIER, 1999).

Em Pernambuco, as políticas públicas até então estabelecidas pelas esferas do poder público, buscam identificar a necessidade de inclusão produtiva de áreas marginalizadas no processo de desenvolvimento que o estado vem vivenciando há algum tempo. Essa estratégia de fomento de áreas produtiva, em especial os arranjos produtivos locais advém de uma perspectiva sistêmica para se desenvolver as microrregiões, dada a sua vocação econômica.

Assim, é de grande importância o estudo dos condicionantes da política de capacitação para inovação ao considerar a necessidade de políticas públicas para alavancar as potencialidades existentes do APL de agricultura orgânica, uma vez que essas comunidades demandam por apoio específico no que concerne a financiamento, capacitação tecnológica e de gestão, entre outros suportes necessários à produção e à inovação, tendo como objetivo o desenvolvimento sustentável, não só do ponto de vista da dinâmica das atividades econômicas que são desenvolvidas, mas, sobretudo, aquelas relacionadas à inovação social que permite uma melhor qualidade de vida as comunidades do APL, a partir da cooperação e construção de valor entre os atores sociais. Dessa forma, o presente trabalho teve como objetivo a análise dos elementos necessários no delineamento da política de capacitação para a inovação do APL de agricultura orgânica no estado de Pernambuco.

\section{Fundamentação Teórica}

\section{Conceituação de um arranjo produtivo local (APL)}

A ação de um polo de desenvolvimento, ao atrair investimentos para um dado local, geralmente cria ou reforça aglomerações de empresas. Essas empresas, na medida em que exportam para outras regiões, reforçam o próprio polo de desenvolvimento: elevam a renda, atraem pessoas e induzem investimentos públicos em infraestrutura. Como consequência, atraem mais empresas, em particular do setor de serviços, para atender à crescente demanda produtiva, pessoal e pública dessa 
região e de regiões anexas. Nesse sentido, aglomeração de empresas é um tema muito importante para os estudos de desenvolvimento regional (BNDES, 2005).

De acordo com Cassiolato e Lastres et al. (2003), esses aglomerados são denominados de Arranjos Produtivos Locais, APL, que dizem a respeito a um aglomerado territorial de agentes econômicos, políticos e sociais, que buscam desenvolver uma atividade econômica principal - que apresentam vínculos mesmo que incipientes - em um mesmo espaço geográfico (regional ou local). Envolve a participação de empresas complementares ou suplementares, desempenhando a função de produtoras ou fornecedoras de insumos, equipamentos, prestando consultoria e serviços, além de outras instituições públicas ou privadas que criam mecanismos para o fomento do APL na região, como o governo (estadual e/ou federal), instituições de crédito, ensino e pesquisa, cooperativas, associações.

O que reforça o argumento dos APL tratar-se de aglomerados de diversos atores é o fato de que onde houver a produção de um bem ou serviço sempre haverá um arranjo em torno de um mesmo para lhe proporcionar o suporte necessário a montante e a jusante na cadeia produtiva do arranjo, envolvendo atores relacionados ao fornecimento de insumos, equipamentos, mão de obra, conhecimento, capacitação, comercialização dos produtos. Dessa forma, o conceito aqui discutido possui relação sistêmica com o meio no qual se insere, tanto em dimensões externas quanto internas.

Além do mais, dentro de um APL é de grande importância que os seus grupos associativos estejam organizados de forma estruturada e com um bom nível de compreensão, por parte de seus associados, do papel de cada um dentro da estrutura organizativa. Isso possibilita mais acesso a informações sobre novas tecnologias, estratégias de organização e comercialização, possibilidades de se produzir melhor e com mais eficiência e qualidade, além da formação de grupos de interesse comum no sentido de consolidar um otimizado processo de gestão das atividades econômicas e produtivas.

\section{A agricultura familiar}

A agricultura familiar é aquela onde os membros familiares tem acesso estável à terra, seja de forma de propriedade, seja mediante algum tipo de usufruto, com predominância do trabalho familiar, podendo existir, de forma adicional, o uso de mão de obra externa, possuindo auto subsistência e uma vinculação permanente ou temporária com o mercado. Além disso, possui algum grau de autonomia na gestão das atividades agrícolas, como por exemplo, poder de decisão com relação ao o que plantar e quanto plantar de acordo com as necessidades internas e do mercado, como dispor dos excedentes, da terra, entre outros (ALTAFIN, 1987). 
A agricultura familiar brasileira exerce forte papel na produção de alimentos no país. Segundo dados do IBGE, 84,4\% dos estabelecimentos rurais no Brasil têm uma base familiar composta por 4.367 .902 produtores, sendo responsável por mais de $80 \%$ dos produtos produzidos internamente. O Nordeste contribui com 2.187.295 estabelecimentos, 50,08\% deste total. Pernambuco aparece em terceiro lugar, com 275.740 (12,6\% do total da região nordeste e 6,3\% do total nacional) (IBGE, 2009).

Em Pernambuco, a base econômica da agricultura familiar está relacionada principalmente à produção de arroz em casca, feijão, mandioca, milho em grãos, bovino de leite, caprino, aves e suínos. Os expressivos resultados da agricultura familiar vão além da produção de alimentos, pois 12,3 milhões de trabalhadores no campo estão em estabelecimentos da agricultura familiar, o que representa quase três quartos do total de pessoas ocupadas no meio rural, fazendo da atividade deste setor uma importante forma de fixar o homem no campo, evitando sua migração para os grandes centros urbanos e todas as suas consequências, outro fator que justifica os investimentos realizados pelo Governo Federal (IBGE, 2009).

No entanto, a agricultura familiar no estado de Pernambuco, assim como em outras regiões do país, possui grandes entraves para o seu pleno desenvolvimento, tais como: ineficiência dos processos produtivos, com baixo nível tecnológico, de formação, de assistência técnica, de capacidade gerencial e de organização; dificuldade de acesso ao crédito e a informação, de se associar, produzir e comercializar; a baixa escolaridade. Dessa forma, cabe aos órgãos de fomento que possuem no seu cerne a agricultura familiar como objeto estabelecer políticas públicas adequadas para sanar essas dificuldades e criar mecanismos para o seu desenvolvimento.

\section{Metodologia}

O presente trabalho é constituído por um estudo exploratório, uma vez que busca por uma familiarização como o fenômeno social complexo a fim de torná-lo mais explícito (GIL, 1999). Utilizou-se o método de estudo de caso que busca a observação e a descrição holística e intensa de seus processos e fundamentos de um fenômeno bem delimitado em sua complexidade, não se tratando de uma escolha metodológica em si, mas a escolha de um determinado objeto a ser estudado que compartilhem o mesmo ambiente e as mesmas experiências (STAKE apud GODOY, 2006).

Além do mais, o fenômeno estudado não pode estar isolado de seu contexto social, cultural e econômico. O método do estudo de caso, segundo Hartley apud Godoy (1995), tem permitido rastrear processos de mudanças, identificando forças históricas, pressões contextuais e a dinâmica de vários grupos que interferem no objeto de estudo. 
Sob a égide da metodologia do estudo de caso, utilizou-se a sua forma interpretativa que, além de conter uma rica descrição de um fenômeno, busca encontrar padrões nos dados e desenvolver categorias conceituais que possibilitem ilustrar, confirmar ou opor-se a suposições teóricas (GODOY, 2006), ou seja, a partir de dados empíricos coletados por meio de entrevistas desenvolve-se um conjunto integrado de conceitos e suas interações.

No momento da análise, foi utilizada a técnica de análise do conteúdo, por utilizar um conjunto de técnicas de análise de comunicações, que utiliza procedimentos sistemáticos e objetivos de descrição do conteúdo das mensagens, indicadores que permitem a inferência de conhecimentos relativos às condições de produção/recepção dessas mensagens (BARDIN, 1994). Essa técnica é bastante rica por enriquecer a tentativa exploratória e aumentar a propensão da descoberta. No presente trabalho foram seguidas as etapas básicas da análise do conteúdo, de acordo com Bardin (1994).

A primeira foi a pré-análise onde ocorreu toda a organização do material que ajudou a entender melhor o APL de agricultura orgânica. Na segunda etapa, a descrição analítica, o material reunido foi mais bem aprofundado, pesquisando por meio de relatórios, editais de seleção de novos integrantes do PAIS e reportagens e já estruturando uma linha de raciocínio. Na última etapa, a interpretação inferencial, a análise propriamente dita, por meio do embasamento no material coletado ocorreu a reflexão, intuição, conexão de ideias, identificação do ator que age potencialmente no APL, não mais invisível, que contribui para a inserção produtiva e social das comunidades daquela localidade.

\section{Resultados e Discussão}

\section{Programas de incentivo ao desenvolvimento do APL de agricultura orgânica}

Nos últimos anos, o governo de Pernambuco vem adotando como estratégia de desenvolvimento sustentável para a agricultura orgânica, ações que busquem garantir a integração econômica dos arranjos produtivos locais, revitalizando atividades tradicionais, identificando novas vocações e estimulando o empreendedorismo.

Segundo o relatório do Prorural (Programa de apoio ao desenvolvimento rural sustentável de Pernambuco) que tem como missão coordenar, implementar e apoiar políticas de desenvolvimento rural sustentável, voltadas para a melhoria da qualidade de vida das comunidades rurais de Pernambuco, atuando em 180 municípios de 12 regiões de desenvolvimento do estado (2011), as políticas federal e estadual para apoio à agricultura familiar em Pernambuco, apresentam um corpo diversificado de programas e projetos de ação governamental. 
Identificou-se 36 (trinta e seis) programas, projetos e mecanismos institucionais, com finalidades e possibilidade de apoiar a competitividade da agricultura familiar em Pernambuco. Entre esses programas identificados, dez agem no APL de agricultura orgânica, eles estão listados no quadro abaixo.

Quadro 1 - Programas, Projetos e Mecanismos de apoio ao APL de Agricultura Orgânica da Zona da Mata Pernambucana. Fonte: PRORURAL - Relatório Agroecologia, 2011.

\begin{tabular}{|c|c|c|}
\hline $\begin{array}{l}\text { Programas, Projetos e } \\
\text { Mecanismos } \\
\text { Institucionais. }\end{array}$ & $\begin{array}{l}\text { Órgão/Agente } \\
\text { Executor }\end{array}$ & Finalidade \\
\hline $\begin{array}{l}\text { PRONAF - Programa } \\
\text { Nacional de Fortalecimento } \\
\text { da Agricultura Familiar. }\end{array}$ & $\begin{array}{c}\text { MDA, BNDES, } \\
\text { Banco do Brasil e } \\
\text { Banco do Nordeste } \\
\text { do Brasil }\end{array}$ & $\begin{array}{l}\text { Apoio financeiro as atividades agropecuárias e não } \\
\text { agropecuárias exploradas mediante a um emprego direto da } \\
\text { força do trabalho da família produtora rural. }\end{array}$ \\
\hline $\begin{array}{l}\text { PROGER - ÀREA RURAL } \\
\text { Programa de Geração de } \\
\text { Emprego e Renda. }\end{array}$ & $\begin{array}{l}\text { Ministério do } \\
\text { Trabalho e } \\
\text { Emprego - MTE } \\
\end{array}$ & $\begin{array}{l}\text { Financiamentos de investimentos de longo prazo, com ou sem } \\
\text { capital de giro associado ao investimento, para gerar e manter } \\
\text { emprego e renda. }\end{array}$ \\
\hline $\begin{array}{l}\text { Programa Nacional de } \\
\text { Microcrédito Produtivo } \\
\text { Orientado }\end{array}$ & BNDES & $\begin{array}{l}\text { Facilitar e ampliar o acesso ao crédito entre os } \\
\text { microempreendedores formais e informais; disponibilizar } \\
\text { recursos para o microcrédito produtivo orientado. }\end{array}$ \\
\hline $\begin{array}{l}\text { PTA - Programa de Apoio } \\
\text { as Tecnologia Apropriadas }\end{array}$ & $\begin{array}{l}\text { Ministério da } \\
\text { Ciência e } \\
\text { Tecnologia - } \\
\text { MCT/CNPQ }\end{array}$ & $\begin{array}{l}\text { Apoio à capacidade local e regional para gerar a difundir o } \\
\text { progresso técnico almejando o aumento da oferta de tecnologias } \\
\text { a serem utilizadas pelo setor produtivo; Desenvolver tecnologias } \\
\text { apropriadas a serem adotadas por micro e pequenos } \\
\text { empreendedores; Garantir que os processos de capacitação, } \\
\text { seleção, aperfeiçoamento, geração, transferência e difusão de } \\
\text { tecnologias sejam criados e geridos nas próprias comunidades } \\
\text { objetivando sua autodeterminação tecnológica. O Programa } \\
\text { apoia cooperativas de produtores com bolsas, custeio e capital. }\end{array}$ \\
\hline $\begin{array}{l}\text { Desenvolvimento Territorial } \\
\text { - Territórios da Cidadania. }\end{array}$ & MDA /SDT & Apoio a projetos produtivos e de infraestrutura. \\
\hline $\begin{array}{c}\text { DRS - Desenvolvimento } \\
\text { Regional Sustentável }\end{array}$ & Banco do Brasil & Apoio a projetos produtivos e de infraestrutura. \\
\hline $\begin{array}{l}\text { PAA - Programa de } \\
\text { Aquisição de Alimentos. }\end{array}$ & MDS / CONAB & $\begin{array}{l}\text { Incentivar a agricultura familiar compreendendo ações } \\
\text { vinculadas à distribuição de produtos agropecuários } \\
\text { pessoas em Insegurança Alimentar e à Formação de Estoques. }\end{array}$ \\
\hline $\begin{array}{l}\text { Programa de Microcrédito } \\
\text { Rural } \\
\text { (Agroamigo) }\end{array}$ & $\begin{array}{l}\text { Banco do Nordeste } \\
\text { do } \\
\text { Brasil S.A. }\end{array}$ & $\begin{array}{l}\text { Crédito para agricultores de base familiar com renda bruta anual } \\
\text { de até } \mathrm{R} \$ 6 \text { mil. Inclusão bancária do agricultor familiar. }\end{array}$ \\
\hline $\begin{array}{l}\text { TECNOLOGIA Programa } \\
\text { de Apoio ao } \\
\text { Desenvolvimento } \\
\text { Tecnológico. }\end{array}$ & $\begin{array}{l}\text { Banco do Nordeste } \\
\text { do } \\
\text { Brasil S.A. }\end{array}$ & $\begin{array}{l}\text { Financiar empreendimentos que promovam a geração, } \\
\text { incorporação e difusão de inovações tecnológicas. }\end{array}$ \\
\hline $\begin{array}{c}\text { ATER Programa de } \\
\text { Assistência Técnica e } \\
\text { Extensão rural; Pesquisa e } \\
\text { Desenvolvimento - P\&D e } \\
\text { Produção de Bens e } \\
\text { Serviços - PBS. }\end{array}$ & $\begin{array}{l}\text { Empresa } \\
\text { Pernambucana de } \\
\text { Pesquisa } \\
\text { Agropecuária } \\
\text { - IPA. }\end{array}$ & $\begin{array}{l}\text { Prestação de assistência técnica e extensão rural, } \\
\text { prioritariamente aos agricultores de base familiar; realização de } \\
\text { obras de infraestrutura hídrica (barragens e poços); gerar e } \\
\text { difundir tecnologias para produtos e sistemas agropecuários e } \\
\text { para processos agroindustriais com vistas ao mercado. }\end{array}$ \\
\hline
\end{tabular}

Diante das grandes expectativas de demanda dos produtos oriundos da agricultura familiar, que observamos no decorrer dos últimos anos, e das mais variadas dificuldades enfrentadas pela atividade produtiva de base familiar em todo o país, apesar do atual ambiente propício ao desenvolvimento destas atividades, o governo do estado, por meio do Prorural, criou o Projeto 
Pernambuco Rural Sustentável - PRS, vinculado à Secretaria de Tecnologia Rural e Programas Especiais e a Secretaria de Agricultura e Reforma Agrária do Estado de Pernambuco - SARA, órgão também vinculado ao governo do estado de Pernambuco.

\section{A tecnologia social PAIS (produção agroecológico integrado e sustentável)}

Uma estrutura fundiária concentrada, pacotes tecnológicos inacessíveis, falta de políticas agrícolas, de acesso ao crédito e de infraestrutura adequada de serviços resultaram no empobrecimento de parcela da população das áreas rurais. Esse quadro levou ao crescimento do êxodo rural e da favelização dos centros urbanos, com consequências desastrosas para o campo e a cidade. Segundo Assis (2006), a adoção de um projeto político nacional coordenado, fundamentado na disseminação de experiências de desenvolvimento baseadas no desenvolvimento humano e nas potencialidades locais, que visem tirar da exclusão social a população marginalizada, incorporandoas ao processo produtivo, é um caminho possível para alcançar o desenvolvimento almejado pelas nações.

Nesse contexto, há alguns anos o Governo Federal vem buscando, por meio de programas, fortalecer e ampliar as ações de segurança alimentar nas regiões brasileiras de baixo índice de IDH e que possuem como cerne de suas atividades as culturas de subsistência. Nesse contexto, o Ministério do Desenvolvimento Social e Combate à Fome (MDS) em parceria com o SEBRAE e a Fundação do Banco do Brasil (FBB), vêm investindo nas unidades de produção agroecológica integrada e sustentável (PAIS) em várias regiões do país. No nordeste, essa tecnologia social, ganha mais notoriedade por se tratar de uma região ainda vulnerável no âmbito das questões tratadas e por apresentarem elevados índices de pobreza e exclusão social, dada a sua relação econômica e social, com relação a outras áreas do Brasil.

A tecnologia social PAIS foi concebida a partir da experiência de pequenos agricultores que optaram por fazer uma agricultura sustentável, sem uso de produtos tóxicos e com a preocupação de preservar o meio ambiente. As ações começaram a ser empregadas em 1999, na região serrana de Petrópolis, no Rio de Janeiro, por uma família de produtores. Em 2005, passaram a ser reaplicadas pela Fundação Banco do Brasil, em parceria com o Serviço Brasileiro de Apoio às Micro e Pequenas Empresas (SEBRAE) e o Ministério da Integração Nacional. Entre 2005 e 2007, com a parceria firmada, foram construídas 1,3 mil unidades PAIS em 33 municípios de 11 estados (Alagoas, Bahia, Ceará, Espírito Santo, Goiás, Minas Gerais, Mato Grosso do Sul, Paraíba, Piauí, Sergipe e Rio Grande do Norte) (FBB, 2012).

Os investimentos sociais da Fundação Banco do Brasil somaram R\$ 3,8 milhões. Para a construção dessas primeiras unidades, outras parcerias foram necessárias, como Coopevales, Unijé, 
Movimento Graal do Brasil e Cáritas de Janaúba. De 2008 a 2011, outras 4.335 unidades foram construídas em 24 estados, além do Distrito Federal: Acre, Alagoas, Amazonas, Bahia, Ceará, Espírito Santo, Goiás, Maranhão, Minas Gerais, Mato Grosso, Mato Grosso do Sul, Pará, Paraíba, Pernambuco, Piauí, Paraná, Rio de Janeiro, Rio Grande do Norte, Rondônia, Roraima, Rio Grande do Sul, Santa Catarina, Sergipe e Tocantins (FBB, 2012).

A filosofia do PAIS é promover uma produção que dispensa o uso de ações que impactam de forma negativa o meio ambiente, como o uso de queimadas, agrotóxicos e desmatamento, assim tem-se a sua dimensão ambiental; é integrada por que não é apenas orientada para a produção de alimentos, mas também a criação de animais e utiliza insumos da propriedade familiar em todo o processo produtivo; busca preservar a qualidade do solo e das fontes de água onde os empreendimentos são instalados o que de certa forma, garante o seus caráter sustentável; e busca a cooperação entre os produtores rurais, em especial os pequenos produtores, auxiliando nas questões referentes a comercialização e questões mercadológicas do seus produtos ofertados ao mercado local ou regional.

$\mathrm{Na}$ denominação utilizada pelo relatório da Fundação do Banco do Brasil (2012) a tecnologia social PAIS é um sistema de produção agroecológico de hortaliças, frutas e pequenos animais, dispostos numa mesma área e de forma circular. Tem como pressuposto a racionalização de recursos. Busca a sustentabilidade econômica e ecológica, a maximização dos benefícios sociais e a minimização da dependência de energia não renovável.

Esse modelo de tecnologia social (TS) se destaca por criar mecanismos para que sejam cultivados e comercializados produtos saudáveis por meio da cooperação entre os agricultores familiares o que reforça e apoia as premissas dos arranjos produtivos locais.

Para nortear como o PAIS funciona, as principais técnicas usadas são: (1) sistema de irrigação por gotejamento, por meio de caixa d'água acima do nível da horta, para aproveitamento da força da gravidade, proporcionando eficiência e racionalização no uso dos recursos hídricos; (2) integração de aves e outros animais, de acordo com a vocação local e regional; (3) reutilização dos resíduos produzidos pelos animais como matéria-prima para produção de composto a ser usado nas plantações; (4) diversificação da produção para o máximo aproveitamento dos nutrientes do solo e auxílio no controle de pragas e doenças; (5) quintal agroecológico para agregar valor à renda familiar com a produção de frutas e raízes (FBB, 2012).

A agroecologia, na medida em que possui como premissa básica uma produção agrícola que não agrida o meio ambiente, resgata a lógica da complexidade presente nas sociedades camponesas tradicionais, integrando propostas agroecológicas com outras voltadas ao desenvolvimento da 
agricultura familiar, a qual, em função da escala, favorece a conciliação entre a complexidade desejada e a supervisão e controle do processo de trabalho necessário (ASSIS, 2006).

A integração proposta por essa TS reforça a proposta de ação local como alternativa para o desenvolvimento, pois, tendo em vista que os agricultores familiares possuem um envolvimento local, viabilizam-se os mercados locais a partir de uma aproximação e orquestramento de interesses entre produtores, comerciantes e consumidores locais, consoante com a lógica dos arranjos produtivos locais. O PAIS parte de um conjunto de princípios que são considerados os pilares para promover o desenvolvimento da produção rural dado o contexto que ele está inserido. Esses princípios que auxiliam a sua implementação são: associativismo e cooperativismo, comercialização, empreendedorismo solidário, gestão do sistema produtivo e prática da agroecologia.

O associativismo e o cooperativismo buscam a união dos produtores rurais voluntariamente de forma estruturada para que seja atingido um objeto comum e benéfico a todos, onde todos possuem o mesmo valor e compartilham não só das suas dificuldades com a produção e gestão, mas, sobretudo, do aprendizado que eles adquirem com a tecnologia PAIS. Trata-se do princípio que o todo é mais forte que a soma das partes. Também se relaciona com as ideias do empreendedorismo solidário e economia solidária.

O princípio da agroecologia insere a dimensão ambiental na prática da agricultura, buscando meio alternativos que respeitem os ciclos naturais e que desenvolvam o cultivo de alimentos orgânicos. Na comercialização são apresentados aos produtores rurais alguns conceitos relacionados a produto, oferta e demanda, embalagens, distribuição, vendas, custos, consumidores, armazenamento, concorrência, planejamento, logística para que os produtores possam incorporá-los em sua propriedade rural e atribuir valor sua produção e produtos no mercado.

No estado de Pernambuco por meio da interferência e incentivo do governo do estado, o modelo do PAIS é operacionalizado pelo IPA (Instituto Agronômico de Pernambuco) que presta assessoria aos agricultores familiares que desenvolvem essa tecnologia e também a ASSOCENE Associação de Orientação às Cooperativas do Nordeste. Entre as principais atividades desses dois atores para o desenvolvimento do APL de agricultura orgânica em Pernambuco está à identificação de quem são os agricultores, implantação do sistema, assessoria e capacitação das famílias beneficiadas. Uma parceria entre o BNDES e ASSOCENE instalaram 88 unidades do PAIS na Zona da Mata de Pernambuco, envolvendo os municípios de Gameleira, Ribeirão, Vitória de Santo Antão, Primavera, Chã Grande, Chã de Alegria, Amaraji, Lagoa de Itaenga, Glória de Goitá e Pombos (municípios do APL de agricultura orgânica). 
Em termos de investimentos, segundo a FBB, foram destinados 59,92\% do total do montante em 2012 para a região nordeste, com Pernambuco absorvendo um total de 20.979 mil reais distribuídos para o desenvolvimento do trabalho, geração de renda e capacitação dos agricultores rurais que adotaram a tecnologia social do PAIS.

Por meio de pesquisa e análises nos relatórios dos órgãos responsáveis pela implementação do PAIS para que um agricultor seja beneficiado pelo programa deve-se atender aos seguintes critérios, que estão em consonância com os objetivos do programa estabelecidos pelo governo federal: ser agricultor familiar, preferencialmente, com a declaração de aptidão do PRONAF; serem famílias de baixa renda, sendo assim considerados aquelas com renda igual ou inferior a um salário mínimo por mês; a família deve possuir, no mínimo, quatro membros em sua composição.

Alternativamente, essas famílias devem ser assentadas por projetos de reforma agrária, ser remanescente de comunidades quilombolas ou de povos indígenas. Assim não se trata da seleção aleatória de famílias a serem incluídas, mas existem critérios rígidos e contratos que mostram a seriedade do que está se implantando e do compromisso que as famílias assumem.

Atualmente, já se pode identificar que os produtos físicos do PAIS são destinados para: (1) Entregas individuais ou coletivas a domicílio ou em ponto/local como lojas de produtos naturais/orgânicos, mercearias, pequenos mercados, supermercados, atacadistas, distribuidoras, empresas, restaurantes, padarias, entre outros. (2) Feiras livres: organizadas pelos próprios produtores e suas cooperativas/associação. (3) Lojas de agricultores: espaço físico pertencente à cooperativa / associação. (4) PAA - Programa de Aquisição de Alimentos (MDS, MAPA/CONAB, MDA) merenda escolar, hospitais públicos, creches, entre outros. (5) Cooperativas / Associações de consumidores: articulação com cooperativas de consumidores para aquisição, comercialização e consumo da produção. (6) Cooperativas que possuam agroindústrias ou processadoras com o mesmo foco. (7) Vendas na propriedade: através do Turismo Rural na Agricultura Familiar.

Para estabelecer um controle das unidades já implementadas pelo PAIS existe uma equipe de assessores técnicos realiza visitas técnicas aos participantes do projeto e reuniões mensais com os grupos de assentados beneficiados para planejamento das atividades e acompanhamento das práticas transmitidas. Além do mais, existe um Sistema de Monitoramento (SIG) com os instrumentos de monitoramento (agenda de atividades, marco zero, visita técnica e atividades diversas), esses são utilizados como fonte de relatório e prestação de contas para órgão de instância superior.

\section{Principais demandas e ações identificadas}


De uma forma mais sistematizada, no Quadro 2 estão apresentadas as principais demandas que os agricultores familiares do APL em estudo apresentavam antes da implementação da tecnologia social PAIS, e as ações que o programa proporcionou e ainda proporciona para melhorar a realidade social desses proprietários.

Quadro 2 - Demandas x Ações necessárias. Fonte: Própria

\begin{tabular}{|c|c|}
\hline Principais Demandas Identificadas & Ações Implementadas Identificadas \\
\hline Necessidade de segurança alimentar das famílias. & $\begin{array}{l}\text { Garantia da segurança alimentar e nutricional, melhor } \\
\text { qualidade de vida e transformação da realidade dos } \\
\text { pequenos proprietários rurais, para superação da pobreza e } \\
\text { crescer de forma estruturada. }\end{array}$ \\
\hline Necessidade de renda. & Geração de trabalho e renda a partir da agricultura familiar. \\
\hline $\begin{array}{l}\text { Não possuíam o domínio sobre as técnicas de plantio } \\
\text { dos alimentos cultiváveis e da criação de animais. }\end{array}$ & $\begin{array}{l}\text { Promoção da participação social (cooperação), respeitando } \\
\text { a cultura local para capacitação e integração entre os } \\
\text { proprietários rurais. Empreendedorismo e associativismo. }\end{array}$ \\
\hline $\begin{array}{l}\text { As famílias que já possuíam alguma plantação ou } \\
\text { criação não possuíam o senso de organização e das } \\
\text { técnicas para gerir as suas atividades para reduzir ao } \\
\text { mínimo o desperdício. }\end{array}$ & $\begin{array}{l}\text { Capacitação de técnicas simples de gestão para organizar a } \\
\text { produção, cultivar a clientela, organizar o orçamento e } \\
\text { planejar a produção para atender periodicamente a clientela, } \\
\text { além de negociar com os centros que distribuem os seus } \\
\text { produtos. }\end{array}$ \\
\hline $\begin{array}{l}\text { O não conhecimento de técnicas simples de vendas e } \\
\text { manuseio dos produtos. }\end{array}$ & $\begin{array}{l}\text { Disseminação da importância dos produtos orgânicos na } \\
\text { economia da região e os seus impactos no meio ambiente } \\
\text { por meio de uma linguagem simples e que os agricultores } \\
\text { possam aprender e disseminar para seus amigos e } \\
\text { familiares. }\end{array}$ \\
\hline $\begin{array}{l}\text { Necessidade de não só de recursos financeiros para o } \\
\text { desenvolvimento das atividades agrícolas, mas de } \\
\text { ajuda técnica por meio de capacitação para } \\
\text { desenvolver as atividades de forma estruturada e } \\
\text { sustentável. }\end{array}$ & \multirow{2}{*}{$\begin{array}{l}\text { Capacitação das técnicas de compostagem, adubação, } \\
\text { marcação, estocagem, plantio de verduras, hortaliças que } \\
\text { mais se adaptam as condições de solo e clima da localidade, } \\
\text { irrigação, técnicas contra pragas, preparação da terra para o } \\
\text { cultivo de uma variedade de produtos. Por meio de uma } \\
\text { linguagem adequada. }\end{array}$} \\
\hline $\begin{array}{l}\text { Sentimento de exclusão e atividades cultiváveis } \\
\text { realizadas de forma individualizada, sem nenhum } \\
\text { esforço de integração entre os pequenos agricultores. }\end{array}$ & \\
\hline
\end{tabular}

Como se percebe, o PAIS não se trata apenas uma metodologia para a instalação de galinheiros e plantação de hortaliças, mas um meio para estabelecer cooperativismo entre os produtos rurais e contribuir para o desenvolvimento do lócus onde a TS está inserida do ponto de vista econômico, social e ambiental, ou seja, o foco não é apenas o desenvolvimento da atividade econômica propriamente dita, mas todo o arranjo que proporciona o suporte para o seu desenvolvimento, assim como a dimensão social inerente ao processo.

\section{Conclusões}

As várias políticas e ações implementadas por diversas instituições públicas e privadas, por vezes não são articuladas ou adequadas para o desenvolvimento dos diversos APLs no Estado. Cada agente busca, por meio de diferentes instrumentos e metodologias de monitoramento e avaliação, selecionar, identificar, avaliar e apoiar os APLs, assim como definir que atores pertencem a esses 
arranjos. A falta de convergência dessas ações e políticas institucionais dificulta a identificação de APLs, bem como o efetivo apoio às suas principais necessidades (LEÃO; MOUTINHO; XAVIER, 2012).

Com um PIB das atividades agropecuárias representando uma parcela incipiente na atividade econômica, incidência de pobreza acima da média do estado e a existência de poucas oportunidades de desenvolvimento para os municípios em que o APL de agricultura orgânica está presente, percebe-se que se trata de uma região carente em termos de capacitação para o seu crescimento em potencial. Assim, surgem a figura do PAIS mantendo o homem no campo e envolvendo a família na concepção de uma produção sistematizada e agroecológica, para ele possa prover a sua subsistência e a comercialização do excedente. Um dos elementos que torna a filosofia do PAIS singular com relação a todos os programas que o governo já implementou, é sem dúvida a capacitação. Não se trata apenas de prover recursos financeiros aos pequenos agricultores da região, é proporcionar tais recursos e capacitá-los cada vez mais por meio de um conjunto de técnicas agrícolas e de administração, com uma linguagem que todos possam compreender e disseminar os fundamentos do programa, e com isso dar-lhe a possibilidade de inserção econômica.

No entanto, os benefícios advindos não são apenas de ordem econômica, mas, sobretudo, sociais por promover uma maior cidadania através da inclusão social dos agricultores nesse processo de aprendizado. Assim, o PAIS consegue promover inovação tecnológica nas práticas operacionais de cunho técnico e a inovação social por causa do processo de aprendizado que proporciona por meio da cooperação que lhe são inerentes.

Identificadas às necessidades de capacitação para a inovação do APL de agricultura orgânica na Zona da Mata Pernambucana, conforme os resultados apresentados no Quadro 2, outras políticas públicas podem ser mais bem direcionados e as já existentes aprimoradas, buscando promover transformações em escala maior as já realizadas e fazer com que os agricultores se beneficiar dos resultados sócio produtivos e se desenvolverem.

\section{Referências}

ALTAFIN, I. Reflexões sobre o conceito de agricultura familiar. 1987. Embrapa. Disponível: http://redeagroecologia.cnptia.embrapa.br/biblioteca/agricultura-familiar/CONCEITO. Acesso em: 29 jan. 2014.

ASSIS, R. L. Desenvolvimento rural sustentável no Brasil: perspectivas a partir da integração de ações públicas e privadas com base na agroecologia. Revista de Economia Aplicada. vol. 10. n. 1. Ribeirão Preto. jan/mar. 2006. 
BANCO NACIONAL DE DESENVOLVIMENTO ECONÔMICO E SOCIAL. Arranjos Produtivos Locais e Desenvolvimento. Rio de Janeiro, 2005.

BARDIN, I. Análise de conteúdo. Lisboa: Edições Setenta, 1994.

BASE DE DADOS DO INSTITUTO BRASILEIRO DE GEOGRAFIA E ESTATÍSTICA - IBGE, 2009.

BOISIER, S. El dessarrolo territorial a partir de la construccion de capital sinergetico. Redes, v. 4, n, 1, p. 61-78, 1999.

CASSIOLATO, J. E., LASTRES, H. M.M. O foco em arranjos produtivos e inovativos locais de micro e pequenas empresas. In: LASTRES, H.M.M.; CASSIOLATO, J.E.; MACIEL, M.L. Pequena empresa: cooperação e desenvolvimento local. Rio de Janeiro: Relume Dumará, 2003. p. 21-34.

FUNDAÇÃO BANCO DO BRASIL. PAIS - Produção agroecológica integrada e sustentável: mais alimento e renda no campo. $1^{\circ}$ ed. 64p. Brasília, 2012.

FURTADO, Celso. Criatividade e dependência na civilização industrial. Rio de Janeiro: Paz e Terra, 1978.

GIL, A.C. Métodos e técnicas de pesquisa social. São Paulo: Atlas, 1999.

GODOY, A.S. Estudo de caso qualitativo. In: GODOI, C.K; BANDEIRA-DE-MELLO, R.; LASTRES, $H$. et al. Interagir para competir: promoção de arranjos produtivos e inovativos no Brasil. Brasília, DF: SEBRAE/FINEP/CNPq, 2002. 354 p.

LEÃO, E. L.S.; MOUTINHO, L.M.G.; XAVIER, M.G.P. Condicionantes de crescimento arranjo produtivo local de apicultura na região do Araripe, Pernambuco. RACE, Unoesc,v. 11, n. 1 Edição Especial Agronegócios, p. 75-102, jan./jun. 2012.

PRORURAL. Análise de políticas públicas de apoio à Agricultura familiar e diagnóstico da Agricultura familiar. Março, 2011.

PRORURAL. Relatório. Relatório de análise dos participantes do PRS, da produção e da comercialização da Agroindústria da polpa de fruta, apicultura e Meliponicultura da agricultura familiar no estado de Pernambuco. 100 f. Março, 2011.

PRORURAL. Diagnóstico dos Arranjos Produtivos do estado e análises de estudo de caso. Março, 2011.

PRORURAL. Relatório da Agroecologia, 2011. 